\title{
En bloc resection of a thoracic chordoma is possible using minimally invasive anterior access: An 8-year follow-up
}

\author{
Anand Goomany, Jake Timothy, Craig Robson, Abhay Rao ${ }^{1}$ \\ Departments of Neurosurgery and ${ }^{1}$ Spinal Surgery, Leeds Teaching Hospitals, NHS Trust, Leeds, UK
}

\section{ABSTRACT}

Thoracic spine chordomas are a rare clinical entity and present several diagnostic and management challenges. Posterior debulking techniques are the traditional approach for the resection of thoracic tumors involving the vertebral body. Anterior approaches to the thoracic spine enable complete tumor resection and interbody fusion. However, this approach has previously required a thoracotomy incision, which is associated with significant perioperative morbidity, pain, and the potential for compromised ventilation and subsequent respiratory sequelae. The extreme lateral approach to the anterior spine has been used to treat degenerative disorders of the lower thoracic and lumbar spine, and reduces the potential complications compared with the anterior transperitoneal/transpleural approach. However, such an approach has not been utilized in the treatment of thoracic chordomas. We describe the first case of an en bloc resection of a thoracic chordoma via a minimally invasive eXtreme lateral interbody fusion approach.

Key words: Chordoma, eXtreme lateral interbody fusion, minimally invasive, polyetheretherketone cage

\section{Introduction}

Chordomas are low grade malignant neoplasms arising from the remnants of the primitive notochord. The gold standard treatment of spinal chordomas is en bloc resection with negative margins. However, this is difficult to achieve without damaging adjacent structures and causing significant morbidity. ${ }^{[1]}$ The standard approach for thoracic chordomas is via a large thoracotomy incision for tumor excision and subsequent stabilization of the vertebral column with rigid fixation materials. ${ }^{[1]}$

We describe the first case of an en bloc resection of a rare thoracic chordoma via a minimally invasive eXtreme lateral interbody fusion (XLIF) approach.

\section{Address for correspondence:}

Mr. Anand Goomany, 32 Hallam Grange Rise,

Fulwood, Sheffield, S10 4BG, UK.

E-mail: anandg@doctors.org.uk

\begin{tabular}{|l|l|}
\hline \multicolumn{2}{|c|}{ Access this article online } \\
\hline Quick Response Code: & Website: \\
\hline & www.ruralneuropractice.com \\
\cline { 2 - 2 } & \\
\hline
\end{tabular}

\section{Case Report}

A 46-year-old man presented with 18 months history of progressively worsening thoracic back pain. Magnetic resonance imaging (MRI) demonstrated a large extradural lesion located on the posterior half of the T11 vertebral body compressing the spinal cord [Figure 1]. The extradural component extended from T10 to T12 with bilateral infiltration of the T11-T12 neural foramen. This was erroneously biopsied and the histology was consistent with a chordoma. Due to the pathology, it was decided that the biopsy tract can be removed through an open posterior approach with disconnection of the vertebra and stabilization. Rather than the traditional thoracotomy, we elected to use the more recent extreme lateral approach to decrease the morbidity of the procedure.

A two-stage procedure was carried out. The initial stage was a posterior thoracic decompression with

This is an open access article distributed under the terms of the Creative Commons Attribution-NonCommercial-ShareAlike 3.0 License, which allows others to remix, tweak, and build upon the work non-commercially, as long as the author is credited and the new creations are licensed under the identical terms.

For reprints contact: reprints@medknow.com

How to cite this article: Goomany A, Timothy J, Robson C, Rao A. En bloc resection of a thoracic chordoma is possible using minimally invasive anterior access: An 8-year follow-up. J Neurosci Rural Pract 2016;7:138-40. 
instrumented fusion. Under image intensifier, pedicle screws were positioned into the pedicles of T9, T10, T11, and L1. The posterior elements of T11 were subsequently removed to expose the spinal cord. Nerve roots at this level were identified bilaterally, and the left nerve root ligated and divided to allow the chordoma to be mobilized from the spinal cord. With the T11 vertebra dissected subperiosteally, the right and left pedicles were disconnected ensuring no tumor spillage. Rods were then connected and the wound was closed with a drain. The patient was then repositioned in the left lateral position. A $5 \mathrm{~cm}$ transverse incision along the line of the rib was made, and the external and internal oblique muscles were dissected, and the pleural cavity was entered. Although a double lumen tube was placed by the anesthetist, the lung was not deflated but merely retracted. A retractor system (NuVasive UK Ltd, Herts, UK) was placed under fluoroscopy between the ribs. Initial attempts were made to preserve the rib, but due to excessive strain on the retractor system, a two-point $5 \mathrm{~cm}$ portion of the rib was resected, which allowed adequate retraction of the ribs and access to the whole of the T11 vertebral body. The pleura and periosteum were dissected off the vertebral body and the disc space above and below was removed to the end plates of the above and below vertebra. As the chordoma was not involved in the anterior part of the vertebra, the vertebra was resected with a chisel leaving an anterior strut. This allowed the rest of the vertebral body with the chordoma intact to be resected en bloc.

An $\mathrm{XPAND}^{\circledR}$-R polyetheretherketone (PEEK) cage (Globus Medical Inc, Audubon, PA, USA) was inserted and expanded into the endplates of T10 and T12 and Actifuse bone graft substitute (Baxter Healthcare Corporation, USA) was packed around the cage [Figure 2]. A chest drain was inserted intraoperatively due to a pleural breach. The patient was successfully extubated immediately postsurgery and was neurologically intact. The chest drain was removed uneventfully after 3 days. Pathology revealed that the chordoma was indeed resected en bloc with no tumor spillage.

At 8-year follow-up, our patient is asymptomatic with complete resolution of his back pain and remains neurologically intact. MRI confirms no evidence tumor residue or recurrence [Figure 3].

\section{Discussion}

Thoracic spine chordomas are rare with only 30 cases reported in the literature. Posterior debulking techniques are the traditional approach for the resection of thoracic tumors involving vertebral body. This has largely been

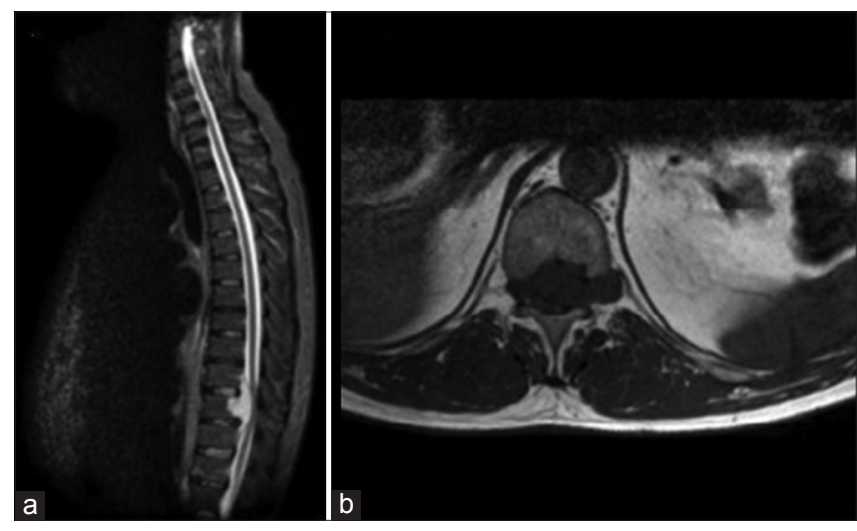

Figure 1: (a) Preoperative sagittal magnetic resonance imaging short tau inversion recovery sequence demonstrating $\mathrm{T} 11$ chordoma (b) axial magnetic resonance T1-weighted sequence

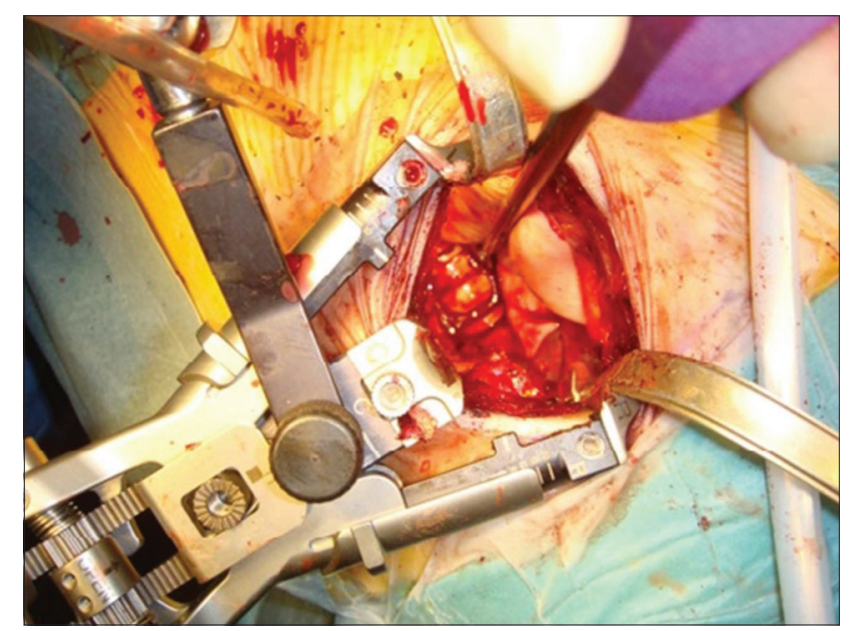

Figure 2: Polyetheretherketone cage inserted into defect to reconstruct the spine

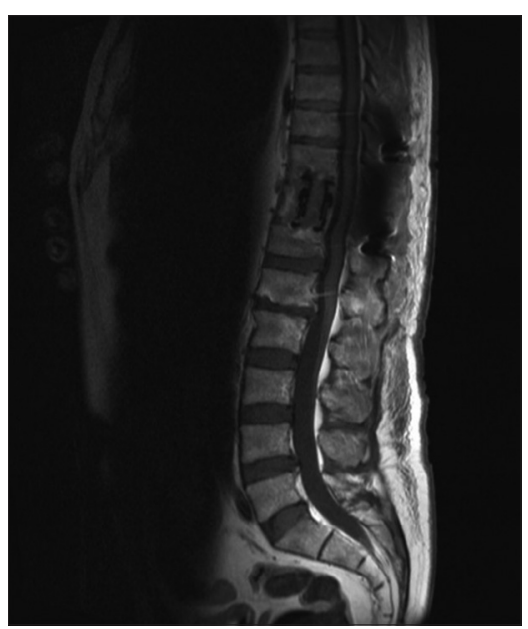

Figure 3: Postoperative sagittal T1-weighted magnetic resonance imaging with gadolinium

replaced by anterior approaches to enable complete tumor resection and interbody fusion. ${ }^{[2]}$ However, this anterior approach has previously required a thoracotomy 
incision, which is associated with significant perioperative morbidity, postoperative pain, and the potential for compromised ventilation. ${ }^{[2]}$ The extreme lateral approach to the anterior spinal column, first described by Pimenta in $2001,{ }^{[3]}$ has been utilized extensively in recent years for degenerative disorders affecting the lower thoracic/ lumbar spine. This novel approach reduces the potential complications compared with the anterior transperitoneal/ transpleural approach to the lower thoracic/lumbar spine. Furthermore, the XLIF approach is associated with less postoperative pain, shorter hospital stays, and rapid return to activities of daily living. ${ }^{[4]}$

Various techniques are used to address the anterior column reconstruction, such as rib graft, titanium cages, and more recently PEEK cages. ${ }^{[5]}$ Titanium cages have the disadvantage of radiation shielding and artefact. ${ }^{[5,6]}$ This potential problem was overcome in our case by the use of a (PEEK) cage, which is a semi-crystal polyaromatic linear polymer, which does not reflect radiation, hence it is superior to titanium cages in oncology patients. ${ }^{[7]}$ Although rib struts are less expensive, removing the rib defeats the objective of providing a minimally invasive less painful approach.

Another advantage of the PEEK cage is its radiolucency, allowing bone fusion to be easily evaluated by standard $X$-ray. Unlike titanium cages, they do not produce artefact on MRI or computed tomography imaging. ${ }^{[7]}$ It is particularly important to avoid implant artefact in the postoperative imaging of chordomas since it is known that these tumors have a high rate of local recurrence. ${ }^{[2]}$

With increasing evidence that aggressive surgical resection is important in spinal tumor surgery, less invasive approaches, which decrease the morbidity in an already immunocompromised group are becoming more important. XLIF is a novel, safe, and effective technique for en bloc excision of thoracic chordomas. Furthermore, the radiotranslucent nature of PEEK cages render them superior to traditional titanium cages for anterior spine reconstruction following vertebrectomy in spinal tumor surgery. Although the authors have previously resected and debulked vertebral body tumors via the XLIF approach, this is the first case of an en bloc resection with an 8-year follow-up with no disease progression.

\section{Acknowledgment}

Mr. Timothy's time was supported by Leeds Musculoskeletal and Biomedical Research Unit (LMBRU)

\section{Financial support and sponsorship}

Nil.

\section{Conflicts of interest}

There are no conflicts of interest.

\section{References}

1. Boriani S, Bandiera S, Biagini R, Bacchini P, Boriani L, Cappuccio M, et al. Chordoma of the mobile spine: Fifty years of experience. Spine (Phila Pa 1976) 2006;31:493-503.

2. Topsakal C, Bulut S, Erol FS, Ozercan I, Yildirim H. Chordoma of the thoracic spine - Case report. Neurol Med Chir (Tokyo) 2002;42:175-80.

3. Pimenta L. Lateral Endoscopic Transpsoas Retroperitoneal Approach for Lumbar Spine Surgery. Paper Presented at: VIII Brazilian Spine Society Meeting; Belo Horizonte, Minas Gerais, Brazil; May, 2001.

4. Ozgur BM, Aryan HE, Pimenta L, Taylor WR. Extreme lateral interbody fusion (XLIF): A novel surgical technique for anterior lumbar interbody fusion. Spine J 2006;6:435-43.

5. Dvorak MF, Kwon BK, Fisher CG, Eiserloh HL $3^{\text {rd }}$, Boyd M, Wing PC. Effectiveness of titanium mesh cylindrical cages in anterior column reconstruction after thoracic and lumbar vertebral body resection. Spine (Phila Pa 1976) 2003;28:902-8.

6. Delacroix S, Rymel J, Smith PJ, Clubb BS. The effects of steel and titanium mandibular reconstruction plates on photon and electron beams. Br J Radiol 1990;63:642-5.

7. Kahraman S, Daneyemez M, Kayali H, Solmaz I, Beduk A, Akay M. Polyetheretherketone (Peek) cages for cervical interbody replacement: Clinical experience. Turk Neurosurg 2006;16:120-3. 